\title{
Scalable Route to Chiral Phosphoramidites
}

\author{
Sergiy G. Krasutsky ${ }^{1}$, Sheila H. Jacobo ${ }^{1}$ \\ ${ }^{1}$ Chemical Development Department, Albany Molecular Research Inc, United States \\ Correspondence: Sergiy G. Krasutsky, Chemical Development Department, AMRI, 3 University Place, Rensselaer, NY, \\ 12144, United States. Phone: +1-518-512-2613. E-mail: Sergiy.Krasutsky@amriglobal.com.
}

Received: April 7, 2016 Accepted: April 15, 2016 Online Published: April 26, 2016

doi:10.5539/ijc.v8n2p64 URL: http://dx.doi.org/10.5539/ijc.v8n2p64

\begin{abstract}
The chiral copper-catalyzed conjugate addition is a well-developed methodology to create asymmetric C-C bonds. Many efforts have been dedicated to design efficient systems and identifying highly efficient ligands. Among the most proficient ligands, the ones possessing a bis-phenol or a bis-naphthol moiety are the most prominent. Herein we describe a scalable convenient route that can afford phosphoramidites in excellent yield.
\end{abstract}<smiles>[R]c1ccc2c(c1)OP([C@@H](C)c1ccccc1)N([C@H](C)c1ccccc1)[C@H](C)c1ccccc1O2</smiles>

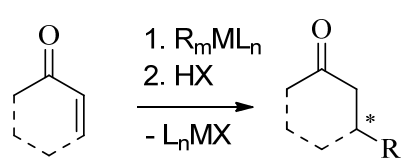

Figure 1. General structure and application of phosphoramidites

Keywords: chiral phosphoramidite, bis-phenol, Asymmetric conjugate addition

\section{Introduction}

The engagement of chiral phosphoramidites as ligands in enantioselective copper-catalyzed conjugate carbon-carbon bond formation using organozinc reagents has become an essential tool in the hands of a synthetic chemist (Ferringa, 2000). A series of chiral ligands have been prepared, particularly the preparation of ligand $\mathbf{3}$ has been described in the literature (Vuagnoux-d'Augustin et al; 2007) and is shown in Scheme 1. This ligand was used in the copper mediated asymmetry-inducing step in a production of taxadienone (Mendoza et al., 2012). However, during the process optimization route of taxadienone (Krasutsky et al., 2015) a substantial quantity of this intermediate was required and thus it was highly desirable to develop a method for preparation of ligand $\mathbf{3}$ that minimized the purification efforts as well as improved the overall yield of the product. The process described within this paper eliminated the silica gel chromatography step and provided a more convenient and efficient approach to chiral phosphoramidites.

\section{Results and Discussion}

Since bis-phenol 2 was not commercially available, a convenient route to make it was also desired. Although compound 2 is known in the literature (Neelamegam et al., 2010) a simple purification method was essential to obtain high quality material. Complete conversion of $\mathbf{1}$ to $\mathbf{2}$ was observed when 1.2 eq. of persulfate was used. The reported purification procedure using silica column purification did not purge closely eluting impurities. Instead, we found that the product can be crystallized from MTBE/heptanes in $60 \%$ yield.<smiles>Cc1ccc(O)c(C)c1</smiles>

Scheme 1. Preparation of bis-phenol $\mathbf{2}$ and corresponding phosphoramidite ligand $\mathbf{3}$.

The second reaction, formation of phosphoramidite 3, was reported to proceed in THF (Vuagnoux-d'Augustin et al; 
2007). However, the reaction was plagued by the precipitation of salts and incomplete conversion. As a result, the decision was made to run the reaction in dichloromethane instead of THF. This change allowed the reaction to exist as a homogeneous solution. The order of addition was also investigated. When phosphorus trichloride was reacted with the bis-phenol 2 prior to the chiral amine addition, the reaction required substantial additional time due to the decreased reactivity of bis-phenoxy phosphino-chloride intermediate. Conversely, when the amine was added prior to the addition of bis-phenol 2 , the desired product was formed in 2 hours and was isolated in $86 \%$ yield (the optimal stoichiometric ratio was found to be chiral amine:PCl3:bis-phenol 2 0.95:1:1). An alumina plug was used for the purification. The reaction was scaled up to $10 \mathrm{~g}$ of the chiral amine to give a quantitative yield of phosphoramidite 3 . Encouraged with this result, we extended this strategy to prepare bis-naphthyl phosphoramidite 5 (Scheme 2). This catalyst was found to be useful for iridium catalyzed amination of allylic carbonates (Leitner et al., 2004).<smiles>Oc1ccc2ccccc2c1-c1c(O)ccc2ccccc12</smiles>

4

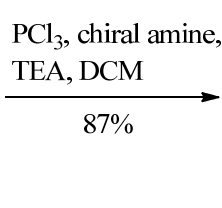

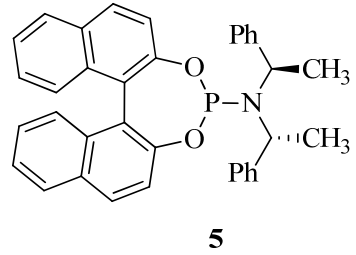

5

Scheme 2. Preparation of bis-naphthyl phosphoramidite 5.

The reaction proceeded as expected and the ligand $\mathbf{5}$ was obtained in quantitative yield. This result demonstrated the overall usefulness of this methodology.

\section{Experimental}

Chemical materials, solvents, and reagents were reagent grade and were used without further purification unless otherwise noted. Reaction progress was monitored using analytical thin-layer chromatography (TLC) on 0.25 -mm Merck F-254 silica gel glass plates. Visualization was achieved by UV light $(254 \mathrm{~nm}) .{ }^{1} \mathrm{H}$ NMR, ${ }^{13} \mathrm{C}$ NMR and ${ }^{31} \mathrm{P}$ spectra were recorded with a Bruker AVANCE $500 \mathrm{MHz}$ spectrometer; chemical shifts were reported in parts per million $(\delta)$ using TMS as the internal standard with coupling constants $(J)$ reported in hertz $(\mathrm{Hz})$.

Synthesis of bis-phenol 2: 5-L, three-neck round bottomed flask equipped with a mechanical overhead stirrer, thermocouple, $\mathrm{N}_{2}$ inlet, and addition funnel was sparged with $\mathrm{N}_{2}$ and charged with iron(II) sulfate heptahydrate (15.0 $\mathrm{g}$, $54.0 \mathrm{mmol}, 0.05$ equiv.), 2,4-dimethylphenol (131 g, $1072 \mathrm{mmol}, 1.00$ equiv.), and water (1.0 L). A solution of sodium persulfate $\left(306 \mathrm{~g}, 1.29 \mathrm{~mol}, 1.20\right.$ equiv.) in water $(1.1 \mathrm{~L})$ was added slowly over 4 hours at $15-25{ }^{\circ} \mathrm{C}$. No significant exotherm was observed. The reaction was stirred overnight. After this time, the reaction was diluted with MTBE/heptanes $(1: 1((\mathrm{v} / \mathrm{v}), 800 \mathrm{~mL})$. The contents of the flask were rested to allow phase separation. The aqueous layer was separated, extracted with MTBE/heptanes $(1: 1(\mathrm{v} / \mathrm{v}), 2 \times 300 \mathrm{~mL})$. The combined organic layers were concentrated, and passed through a silica plug (300 g, 20\% MTBE in heptanes). The fractions containing the product were concentrated. The obtained residue was dissolved in MTBE $(150 \mathrm{~mL})$ and heptanes $(500 \mathrm{~mL})$ were added. The solution was then concentrated down to $300 \mathrm{~mL}$ and heptanes $(500 \mathrm{~mL})$ was added. The solution was stirred overnight affording slurry, and the product was collected by filtration. The filter cake was dried under high vacuum at $35^{\circ} \mathrm{C}$ to afford bis-phenol $2[77.80$ $\mathrm{g}, 60 \%$ yield] as a white solid. IR $\left(\mathrm{KBr}, \mathrm{cm}^{-1}\right): \bar{v}=3520,2920,1465,1210,1185,1115,860,784 .{ }^{1} \mathrm{H} \mathrm{NMR}(500 \mathrm{MHz}$, $\left.\mathrm{CDCl}_{3}\right): \delta 7.00(\mathrm{~m}, 2 \mathrm{H}), 6.86(\mathrm{~m}, 2 \mathrm{H}), 5.06(\mathrm{~s}, 2 \mathrm{H}), 2.28(\mathrm{~s}, 6 \mathrm{H}), 2.27(\mathrm{~s}, 6 \mathrm{H}) .{ }^{13} \mathrm{C} \mathrm{NMR}\left(125 \mathrm{MHz}, \mathrm{CDCl}_{3}\right): \delta 149.2$, 132.0, 130.0, 128.5, 125.2, 122.2, 20.4, 16.2. MS (ESI+): M/z $(\%)=243(100)[\mathrm{M}+\mathrm{H}]^{+}$. CHNS analysis of $2, \mathrm{C}_{16} \mathrm{H}_{18} \mathrm{O}_{2}$ (242): calculated C 79.31, H 7.49; found C 79.21, H 7.35.

Synthesis of ligand 3: A 2-L, three-neck round bottomed flask equipped with a mechanical overhead stirrer, thermocouple, $\mathrm{N}_{2}$ inlet, and addition funnel was sparged with $\mathrm{N}_{2}$, charged with phosphorus trichloride $(6.09 \mathrm{~g}, 44.4 \mathrm{mmol}$, 1.00 equiv.), dichloromethane $(300 \mathrm{~mL})$, and cooled to $0{ }^{\circ} \mathrm{C}$. The mixture was stirred for $30 \mathrm{~min}$. Triethylamine $(22.5 \mathrm{~g}$, 222 mmol, 5.00 equiv.) was added keeping the internal temperature in $0-10{ }^{\circ} \mathrm{C}$ range. A solution of (+)-bis $((R)$-1-phenylethyl)amine (10.0 g, $44.4 \mathrm{mmol}, 1.00$ equiv.) in dichloromethane (100 mL) was added slowly over 20 min at $0-5{ }^{\circ} \mathrm{C}$. The reaction mixture was allowed to warm up to room temperature over 2 hours. A solution of bis-phenol 2 (10.8 g, $44.4 \mathrm{mmol}, 1.00$ equiv.) in dichloromethane $(100 \mathrm{~mL})$ was then added. The reaction was stirred for $2 \mathrm{~h}$, concentrated, and diluted with heptanes $(500 \mathrm{~mL})$. The salts were filtered and washed with heptanes $(\sim 1 \mathrm{~L})$. The combined organic solution was passed through neutral alumina $(200 \mathrm{~g})$. The fractions containing the product were concentrated to afford ligand $3\left[19.0 \mathrm{~g}, 86 \%\right.$ yield] as a white solid. IR $\left(\mathrm{KBr}, \mathrm{cm}^{-1}\right):=3516,2927,1493,1463,1282$, 1214, 1185, 1110, 1064, 962, 861, 787. ${ }^{1} \mathrm{H}$ NMR (500 MHz, $\left.\mathrm{CDCl}_{3}\right): \delta 7.00(\mathrm{~m}, 2 \mathrm{H}), 6.86(\mathrm{~m}, 2 \mathrm{H}), 5.06(\mathrm{~s}, 2 \mathrm{H}), 2.28(\mathrm{~s}, 6$ $\mathrm{H}), 2.27(\mathrm{~s}, 6 \mathrm{H}) .{ }^{13} \mathrm{C}$ NMR $\left(125 \mathrm{MHz}, \mathrm{CDCl}_{3}\right): \delta 147.9\left(J_{\mathrm{C}-\mathrm{P}}=7.6 \mathrm{~Hz}\right), 147.1\left(J_{\mathrm{C}-\mathrm{P}}=2.2 \mathrm{~Hz}\right), 143.4,133.3,132.5,131.3$, $131.2,131.0,130.9,130.2,130.1,130.0,129.3,128.1,128.0,127.9,127.6,126.5,52.5,52.4,20.8,20.7,17.3,16.3 .{ }^{31} \mathrm{P}$ 
NMR (202 MHz, CDCl $): \delta$ 142.3. MS (ESI+): M/z $(\%)=496(100)[\mathrm{M}+\mathrm{H}]^{+}$. CHNS analysis of $3, \mathrm{C}_{32} \mathrm{H}_{34} \mathrm{NO}_{2} \mathrm{P}(495)$ : calculated. C 77.55, H 6.91; N 2.83; found C 77.49, H 6.26, N 2.86.

\section{Conclusion}

Herein we described a useful procedure to prepare chiral phosphoramidites in excellent yield. The process described within this paper eliminated the silica gel chromatography step and provided a more convenient and efficient procedure to chiral phosphoramidites.

\section{References}

Ferringa, B. L. (2000). Phosphoramidites: Marvellous ligands in catalytic asymmetric conjugate addition. Accounts of Chemical Research, 33, 346-353. http://dx.doi.org/10.1021/ar990084k

Krasutsky, S. G., Jacobo, S. H., Tweedie, S. R., Krishnamoorthy, R., \& Filatov A. S. (2015). Route Optimization and Synthesis of Taxadienone. Organic Process Research and Development, 19(1), 284-289. http://dx.doi.org/10.1021/op500314c

Leitner, A., Shu, C., \& Hartwig, J. F. (2004). Editing the stereochemical elements in an iridium catalyst for enantioselective allylic amination. Proceedings of the National Academy of Sciences of the United States of America, 101(16), 5830-5833. http://dx.doi.org/10.1073/pnas.0307967101

Mendoza, A., Ishihara, Y., \& Baran, P. S. (2012). Scalable enantioselective total synthesis of taxanes. Nature Chemistry, 4, 21-25. http://dx.doi.org/10.1038/nchem.1196

Neelamegam, R., Palatnik, M. T., Fraser-Rini, J., Slifstein, M., Abi-Dargham, A., \& Easwaramoorthy, B. (2010). An unprecedented oxidative trimerization of sesamol catalyzed by laccases. Tetrahedron Letters, 53(26), 2497-2499. http://dx.doi.org/10.1016/j.tetlet.2010.02.173

Vuagnoux-d'Augustin, M., \& Alexakis, A. (2007). Copper-Catalyzed Asymmetric Conjugate Addition of Trialkylaluminium Reagents to Trisubstituted Enones: Construction of Chiral Quaternary Centers. Chemistry A European Journal, 13(34), 9647-9662. http://dx.doi.org/10.1002/chem.200701001 


\section{Appendix A}

\section{The NMR spectra for the prepared compounds}<smiles>[2H]c1cc([B])c([B])c(-c2c([B])cc([B])cc2[B])c1</smiles>

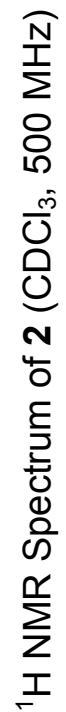

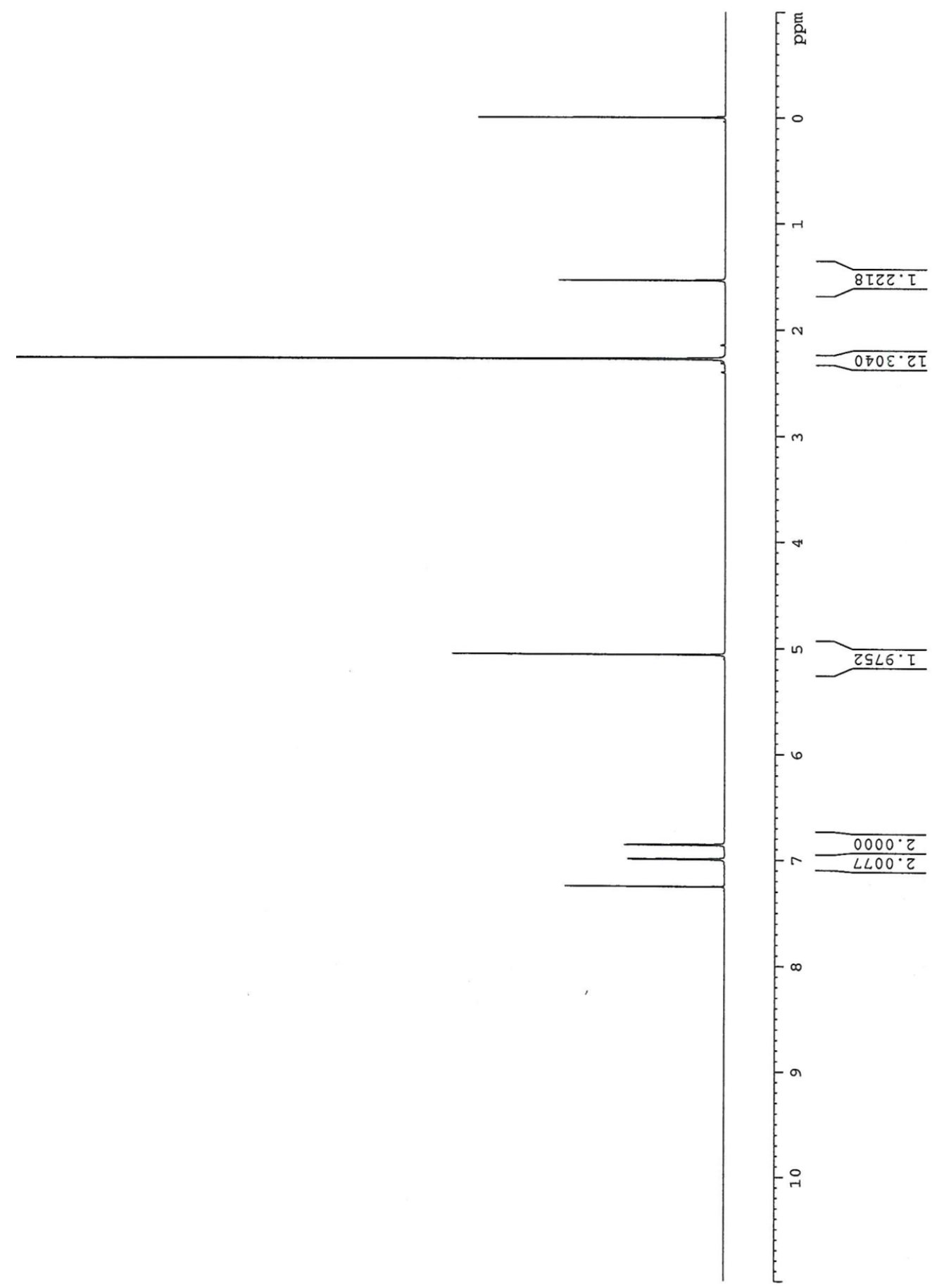



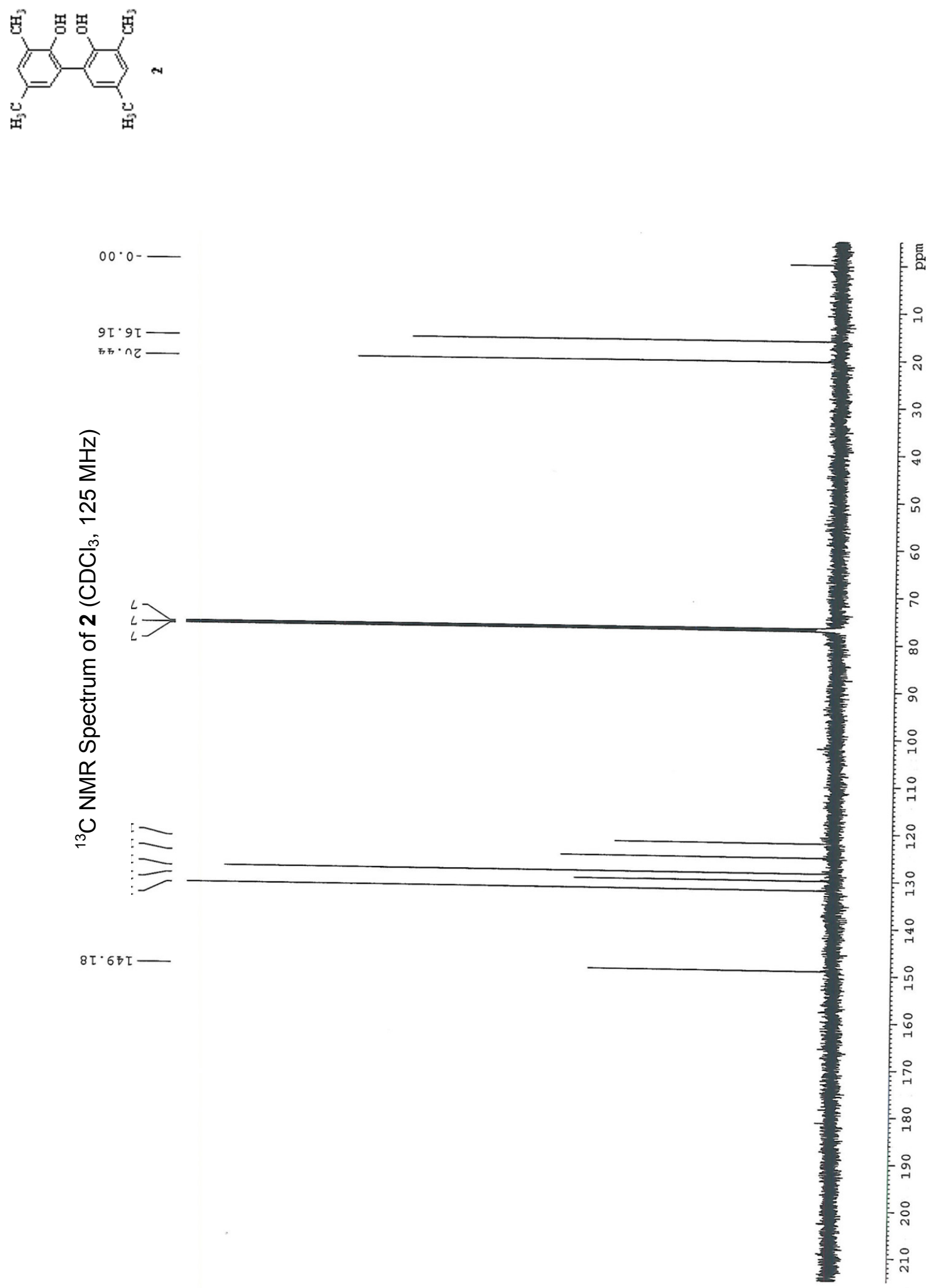

$8 \tau \cdot 6 \pi \tau$ 
<smiles>[2H]c1cc([B])c2c(c1)-c1cc([B])cc([B])c1OC(=C(C([B])[B])C([B])[B])O2</smiles>

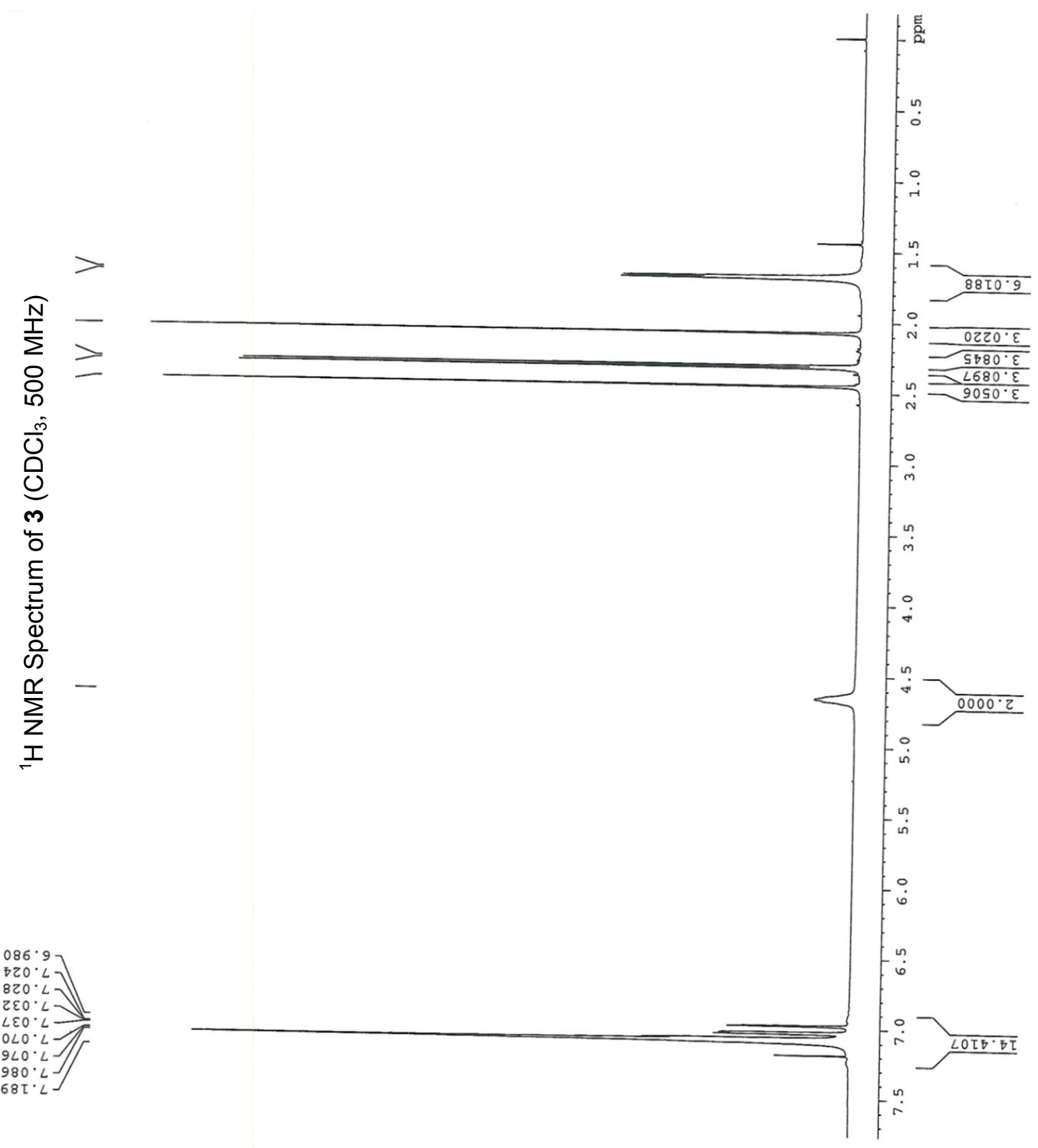



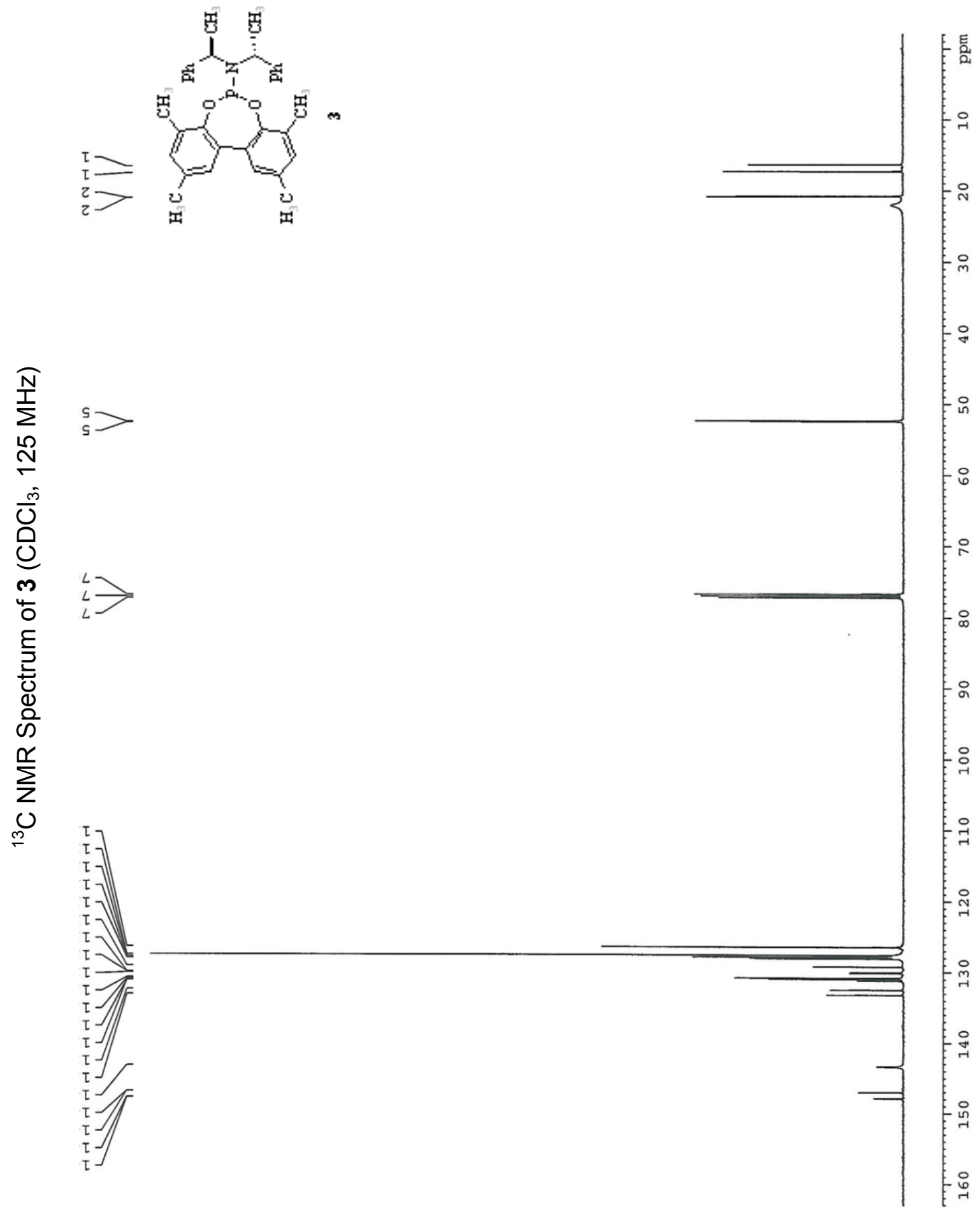


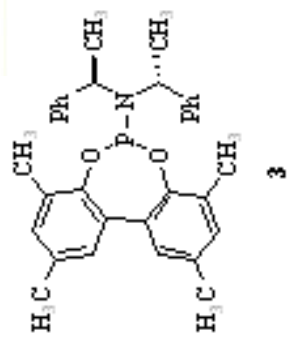

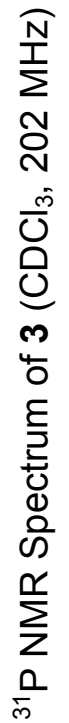

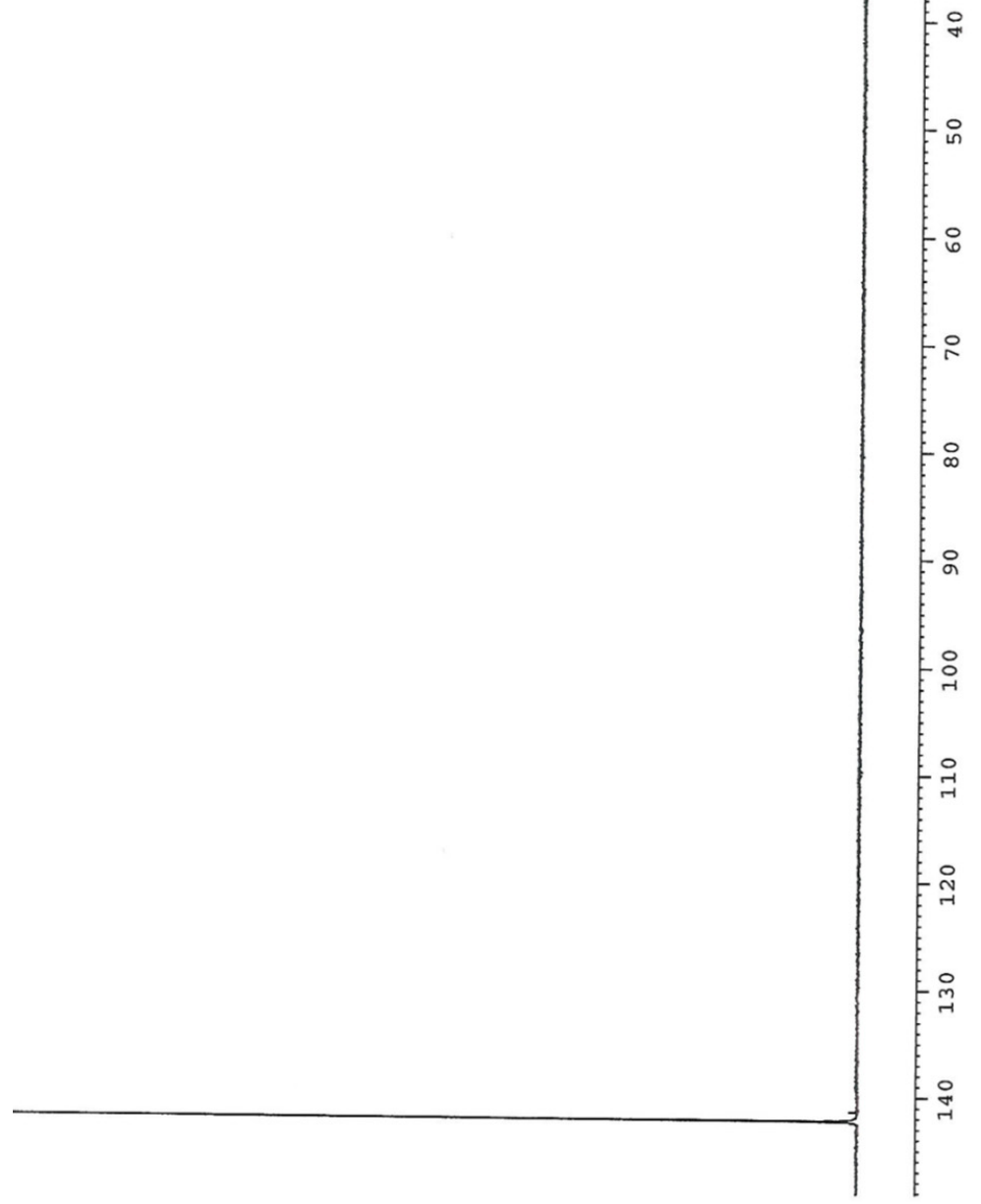

\section{Copyrights}

Copyright for this article is retained by the author(s), with first publication rights granted to the journal.

This is an open-access article distributed under the terms and conditions of the Creative Commons Attribution license (http://creativecommons.org/licenses/by/3.0/). 